\title{
Impact of cataracts and cataract surgery on quality of vision
}

Impacto da catarata e da cirurgia de catarata na qualidade da visão

\author{
Eirini Skiadaresi', Colm McAlinden" \\ ABM University Health Board, Swansea, United Kingdom
}

'MD, MSc, FEBO. Ophthalmologist, Department of Ophthalmology, Singleton Hospital, ABM University Health Board, Swansea, United Kingdom.

"MB BCh, BSc (Hons), MSc, PhD. Doctor, Department of Surgery, Morriston Hospital, ABM University Health Board, Swansea, United Kingdom.
We read with interest the letter to the editor by Fazzi and colleagues who report a negative correlation between anxiety (measured with the IDATE) and quality of life (measured with the WHO-QOL-BREF) in 52 patients with cataracts. ${ }^{1}$ They state: "This finding corroborates previous studies that have demonstrated low quality-of-life scores among patients with cataracts ${ }^{2}$..."

We would like to clarify that the cited paper did not assess quality of life in patients with cataracts and hence did not demonstrate low quality-of-life scores among patients with cataracts. ${ }^{2}$ The study assessed a different latent trait - quality of vision, using the Rasch-scaled Quality of Vision (QoV) questionnaire. ${ }^{3,4}$ The QoV was completed before and three months after cataract surgery in 212 patients across four groups: first or second eye surgery, with or without ocular comorbidity. The study found that cataracts in one or both eyes causes a similar loss in subjective quality of vision, which is also irrespective of the presence of ocular comorbidity. Cataract surgery resulted in a large and comparable improvement in subjective quality of vision, regardless of ocular comorbidity and first or second eye surgery. ${ }^{2}$ These improvements in quality of vision are in line with improvements using visual function and quality of life questionnaires following cataract surgery, which may indicate a relationship between these latent traits. ${ }^{5,6}$ 


\section{REFERENCES}

1. Fazzi L, Dobrianskyj FM, Reggi JR, et al. The influence of anxiety on quality of life among patients with an indication for cataract surgery. Sao Paulo Med J. 2015;133(2):160-1.

2. Skiadaresi E, McAlinden C, Pesudovs K, et al. Subjective quality of vision before and after cataract surgery. Arch Ophthalmol. 2012;130(11):1377-82.

3. McAlinden C, Pesudovs K, Moore JE. The development of an instrument to measure quality of vision: the Quality of Vision (QoV) questionnaire. Invest Ophthalmol Vis Sci. 2010;51(11):5537-45.

4. McAlinden C, Skiadaresi E, Gatinel D, et al. The Quality of Vision questionnaire: subscale interchangeability. Optom Vis Sci. 2013;90(8):760-4

5. Gothwal VK, Wright TA, Lamoureux EL, et al. Improvements in visual ability with first-eye, second-eye, and bilateral cataract surgery measured with the visual symptoms and quality of life questionnaire. J Cataract Refract Surg. 2011;37(7):1208-16.

6. McAlinden C, Gothwal VK, Khadka J, et al. A head-to-head comparison of 16 cataract surgery outcome questionnaires. Ophthalmology. 2011;118(12):2374-81.

Editor's note: The authors of the article "The influence of anxiety on quality of life among patients with an indication for cataract surgery" chose not to send a reply to this letter.

Sources of funding: None

Conflict of interest: None

Date of first submission: July 23, 2015

Last received: July 23, 2015

Accepted: August 1, 2015

\section{Address for correspondence:}

Colm McAlinden

Department of Surgery

Morriston Hospital, ABM University Health Board

Heol Maes Eglwys, Morriston, Swansea, SA6 6NL

United Kingdom

E-mail: colm.mcalinden@gmail.com 